\title{
Relativity Displacement of Spectral Lines and Stellar Constitution.
}

NOT many months ago, a very careful and critical examination by Dr. C. E. St. John of the wave-lengths of the lines in the solar spectrum was sufficient to convince a large body of astronomers that the displacement towards the red of spectrum lines originating in a region of high gravitational potential, required by Einstein's theory of relativity, was an actual phenomenon. An element of doubt remained, however, owing to the exceedingly small amount of the displacement in question and the unknown effects of convection currents and other disturbing influences in the solar atmosphere.

At the time when Dr. St. John's investigation was made, it appeared that no source of light other than the sun could afford a satisfactory test of Einstein's prediction; and that for two reasons. In the first place, the smallness of the displacement to be measured demanded a degree of dispersion and perfection of detail in the spectrum which it was impossible to obtain with the light of any other astronomical body. The relativity displacement depends on the gravitational potential at the surface of a star-that is, on the star's mass divided by its radius - and for no star was this quantity believed to be large enough to give a displacement of more than one or two hundredths of an Ångström unit. In the second place, owing to the identical character of the relativity displacement and the Doppler displacement arising from motion of a source of light away from the observer (both displacements are proportional to the wave-lengths of the lines concerned), it was necessary to select a body the motion of which relative to the earth was known from independent evidence. Since the radial velocities of the stars can be obtained only by means of the Doppler effect, the sun was for this reason also the only body available for the Einstein test.

The restriction thus doubly imposed has now been removed, thanks jointly to some remarkable theoretical predictions by Prof. A. S. Eddington and the extremely fortunate circumstance that Nature has provided a means of testing those predictions. Certain facts of observation recently led Eddington to the conclusion -which he immediately saw to be a natural consequence of his theory of the constitution of the interior of a star-that matter under stellar conditions might attain densities many thousand times greater than those with which we are familiar among terrestrial materials. Not only so, but in the stars known as "white dwarfs," of which two are known, it appeared that these high densities might actually be realised.
These stars are abnormally faint for their spectral type and colour-a fact which suggests that they have very small surface areas and correspondingly large densities ; a given spectral type or colour denotes a definite surface brightness per unit area, and an abnormally small total output of light must therefore mean an abnormally small radiating area. Further, the stars are members of binary systems, and their masses can be determined and hence the order of magnitude of their densities. One of the white dwarfs is a companion of Sirius, and therefore one of the nearest of the stars. This fortunate circumstance has just enabled Dr. W. S. Adams of Mount Wilson Observatory (Proc. Nat. Acad. Sci., Vol. I I, No. 7, July 1925) to observe its spectrum in spite of its low intrinsic brightness, and thereby to confirm both Eddington's prediction and the reality of the Einstein gravitational displacement.

The existence of stars having the extraordinary qualities of the white dwarfs removes the necessity of confining the Einstein test to the sun. The extreme compression of the material of the star involves a very high value of the gravitational potential at the surface, and the relativity displacements are of the order of half an Ångström unit. There is therefore no need to use the high dispersion which would be necessary with normal stars. Further, owing to the fact that the star is a companion of Sirius, the space velocity of the two stars must be the same when allowance is made for the orbital motion. All that it is necessary to observe, therefore, is the difference in displacement between the lines of Sirius and those of its companion. This difference, except for the known amount due to orbital motion, must therefore be due to the excess of Einstein displacement in the companion over that in Sirius itself. Working on these lines, Dr. Adams has found almost indubitable evidence of the existence of an Einstein shift of the expected order, and a mean density of the order of 53,000 (water $=\mathrm{x}$ ).

This remarkable result, which marks a very definite advance in our knowledge of both the foundations of science and the constitution of matter, is interesting on account of the chance which has made it possible as well as for its own intrinsic importance. Had it not been for the fact of the existence of a white dwarf which is, at the same time, one of the nearest of the stars and a member of a binary system of which the other star is a normal one, the confirmation could not have been made.

\section{Current Topics and Events.}

Is Die Naturwissenschaften of July I 7 there appears a report of an address by Prof. Miethe on the production of gold from mercury, from which it seems that, in a mercury vapour lamp operated under suitable conditions, gold actually makes its appearance in amounts amenable to chemical tests. The necessary conditions are rather difficult to define, but with a suitable form of discharge, the gold yield is proportional to the current strength and the time. A definite potential is necessary before any appreciable quantity is observed. A mercury vapour lamp in vacuo is ineffective, but the same discharge in air at atmospheric pressure gives measurable amounts of gold. Again, gold is found after a discharge between two mercury electrodes in paraffin wax; in this case the gold makes its appearance not in the liquid mercury but in the wax along the path of the discharge. In certain experiments even greater quantities of a metal which closely resembles silver are found. 
These results are largely confirmed by Prof. Nagaoka's work recently described in NATURE of July I8, p. 95. Prof. Miethe attributes the appearance of the gold to the disintegration of mercury atoms under the influence of electronic bombardment. In this report no reference is made to the energetics of the problem, nor is any suggestion given as to the mechanism of disintegration. The author admits that the appearance of silver, if silver it is, as a disintegration product of mercury is certainly not to be expected, although, under suitable energy conditions, the conversion of mercury into gold might be anticipated. In the same issue there is published a letter from Dr. Hönigschmidt giving 197.26 as the atomic weight of the gold thus produced, a value identical with that of ordinary gold. This determination, in conjunction with Dr. F.W. Aston's measurements of the isotopes of mercury reported in a letter to NATURE of August 8, p. 208, throws doubt on the transmutation theory.

THE Forestry Commissioners' fifth annual report for the year ending September 30, 1924, shows that steady progress in the work of afforestation in Great Britain has been maintained. During the five years, I9I9-I924, the area actually planted by the Forestry Commission was 39,469 acres, of which 37,790 acres were with conifers and $x 679$ acres with oak, beech, and other hardwoods. In addition, grants made to public bodies and private persons have resulted in the planting (or preparation, with undertaking to plant) of 42,082 acres. The total area planted under the auspices of the Commission was thus $8 \mathrm{I}, 55 \mathrm{I}$ acres. The Commissioners' planting work is entirely dependent on the timely acquisition of suitable land and on the raising of sufficient young trees in forest nurseries. It is satisfactory then to learn that the Commission has acquired $\mathrm{I} 4 \mathrm{I}, 470$ acres of plantable land, of which approximately Ioo,ooo acres represent an addition to the existing forest area of Great Britain, the remainder being felled or devastated woodlands. The nurseries established are extensive, and last year's planting of I0,5 I9 acres absorbed more than 22 million young trees. On April I, I924, the Crown Woods, aggregating 120,648 acres, were transferred from the Commissioners of Woods and Forests to the Forestry Commissioners, and will be managed on the same principles as estates acquired for afforestation. The sixteen Crown Woods (New Forest, Dean Forest, etc.) and the new areas, thirtyfour in England and Wales and twenty-eight in Scotland, where planting on a large scale is being carried on by the Commission, are shown in two maps. The largest of these planting centres is near Thetford in East Anglia; and here a forest of 20,000 acres is in the making. The report gives a full account of the various forestry operations, and is replete with tables and statistics. It has been issued as a Parliamentary Paper (No. I07, price rs.).

Sir ARthur KeIth's description of, the fragments of the skull found by Mr. Turville-Petre in a cave near the Lake of Galilee, which appeared in the Times of August I4, confirms the preliminary report that it is to be assigned to the Neanderthal type. It departs from that type, however, in certain characters in which it appears to approach the type of modern man. Although resembling most closely the Krapina variety of Neanderthal man, the Galilean man differs from that and all other European specimens in having a narrow and high-vaulted skull, and though the eyebrow ridges are massive and strong, the bone enclosing the brain is not thicker than is the rule among modern Europeans. The breadth above the ear-holes is estimated at I $20 \mathrm{~mm}$. and the extreme length at $200 \mathrm{~mm}$., while the volume of the brain may be inferred to have been little short of that of the average modern Englishman, which measures about I480 c.c. A further note by Mr. Turville-Petre suggests that the flint implements represent a transition culture between Acheulean and Mousterian. The predominant types are coups de poing, mainly small in size, side-scrapers, trimmed flakes, narrow blades, many retouched along one edge, and small amygdaloid flakes retouched on the upper surface to form Mousterian points. Anthropologists await with much interest the fuller report on the skull, and the account of the excavation of the cave to be given by Sir Arthur Keith and Mr. Turville-Petre to the anthropological section at the forthcoming meeting of the British Association at Southampton.

WE have received from Mr. W. Spencer Lake, 248 Valentine Street, Bendigo, Australia, a letter in which he comments on Prof. Lloyd Morgan's article on "Optical Records and Relativity" (NATURE, October I8, I924, p. 577). In view of the divergence of view with respect to interpretation of mental reference to what we speak of as objects of vision, Prof. Lloyd Morgan asked whether it is for the physicist to pronounce judgment. Mr. Spencer Lake is of opinion that though most physicists appear to subscribe to the hypothesis of direct apprehension, yet it is doubtful if many could be found who would assert this unshaken confidence in it. Rather would they admit that they are concerned with sensual images and a "construct-world" formed by them therefrom. It seems to him that the physicist is not called upon to explain to which hypothesis he subscribes because it can in no way affect the physical issue. With regard to the transformations of relativity, they refer not to events in general but to measures and to physical quantities defined by these measures. These measures-spatial and temporal-are arbitrary. They depend upon " local spaces " and "local times." What relativity asserts is that, underlying all points of view and all measures, however arbitrary, there is some element of " invariability,": not in the absolute sense, but in the sense that there is something which is independent of point of view, independent of the particular measure-code adopted, and to be regarded as a "law of Nature." The transformations of relativity apply to the quantitative equations by which these laws are expressed. Thus relativity helps to bring us to a better knowledge of the physical world by eliminating what, in our experience, depends upon the local space and time system, for example, the very special space-time frame of classical mechanics. It is not a question of whether the laws

No. 2912 , VOL. I I 6$]$ 
of classical mechanics stand in need of revision or not, but whether the physical world is the same for us as it was before the advent of relativity.

WE have received Vol. I, Part I of the Journal of the Ipswich and District Natural History Society. It will be remembered that this Society was founded on January I, I924, as the result of an amalgamation of the Ipswich and District Field Club and the Ipswich Scientific Society. The Society now numbers 250 members, and is divided into six sections, dealing respectively with botany, conchology, agriculture, prehistoric archæology, microscopy, and photography. The president is Mr. J. Reid Moir, whose address on "The Antiquity of Man in Ipswich" appears as the first communication in the Journal. Other communications deal with the evolution of the river Stour, by Prof. P. H. G. Boswell; the Suffolk and Essex Crag Pits, by Mr. Alfred Bell, Mr. J. Reid Moir, and the late Mr. S. A. Notcutt; and the Suffolk Coast, by Major E. S. Cooper, who traces changes in the coast-line from the earliest times. In view of the importance of the subject we may direct the special attention of students to the paper by Messrs. Bell, Notcutt, and Reid Moir, in which the two former give a list of the crag pits, the types of deposit to be found in each, and directions for reaching them, while the latter deals with the character of the sub-crag detritus beds, and the implements found therein, as well as sites on which each may be best studied.

THE Report of the Board of Visitors appointed by Congress to inquire into the work of the Bureau of Standards at Washington has been issued, and contains much valuable information as to the benefits which have accrued to the United States from the activities of the Bureau. The motor car industry alone has been able to effect economies amounting to $3,000,000 l$. per annum on account of the investigations on fuels, tyres, and brake linings carried out at the Bureau, while the annual grant to the institution has been less than $400,000 l$. The Board emphasises the necessity of more fundamental scientific research, which runs the risk of being given a secondary position in an establishment on which the public makes demands for immediate and profitable returns. A similar point was made by the president of the Société d'Encouragement pour I'Industrie nationale in France in his address at the recent annual meeting, when he spoke of the importance of aiding those who are carrying out research by placing in their hands the instruments they need and the books and periodicals they must read. Owing to the extensive adoption in France of the English Saturday halfholiday, the number of readers who consult the library of the Society on that day has greatly increased.

H.M. Stationery OfFice has of late earned our gratitude by producing many valuable reports in a form that is not merely cheap but also pleasing. Now it has still further marched with the times by placing on sale (price $3 d$.) at the Government Pavilion of the British Empire Exhibition a "Brief Guide to Government Publications," which is as well and attractively written as any advertisement by a large business house. The section on "Science and Technology" occupies five of the twenty-two pages devoted to a descriptive classification, and that without including archæology, agriculture, or fisheries. For details the reader is referred to the lists issued by the Departments concerned. It is a pity that the Stationery Office should not feel called upon to mention the numerous and important publications of the British Museum; at any rate it publishes the Annual Return of that establishment. But even as it is, the field to which this pamphlet guides one is astonishing in its extent and variety; few can be familiar with more than a small corner of it.

AN interesting account by Francis Buckley of the glasshouses on the Wear in the eighteenth century appears in the Journal of the Society of Glass Technology for June. Between 1696 and I 737 at least three glasshouses were built on the Wear, probably by a syndicate called the " Company of Glass-Owners at Sunderland." It is interesting to note that the owners either let the glasshouses or, failing that, worked them themselves. About I74I, many glassmakers on the Tyne considered it advisable to acquire the two glasshouses at Sunderland, but the project fell through. The paper contains many interesting extracts from contemporary newspapers.

THE ever-increasing interest in the problem of securing a purer atmosphere with its resulting benefits should receive further impetus from the Conference to be held at the Palace Hotel, Buxton, on October 2-5, under the auspices of the Smoke Abatement League of Great Britain. Practical proposals for reducing both domestic and industrial smoke are being prepared by the League for full consideration by those attending, and prominent individuals have agreed to open discussions at various sessions. It is hoped that a constructive programme of useful work will be initiated, the results of which can be reviewed at the Smoke Abatement Exhibition and Conference at Birmingham in 1926.

DURING Lord Burnham's absence abroad the Duke of Atholl has consented to act as chairman of the Special Appeal Committee of the Imperial College of Tropical Agriculture. The first large donation received since he has "fathered" the Fund is one of roool. from Messrs. J. and P. Coats, Ltd. This generous gift, following closely upon a contribution of roool. from the Liverpool Cotton Association, is evidence of the interest which is taken in the Imperial work of the College by the cotton industry. Further contributions from those whose interests lie in tropical agriculture should be sent to Mr. Algernon Aspinall, Secretary, The Imperial College of Tropical Agriculture, I4 Trinity Square, London, E.C.3.

Dr. Geza Róheim, of Budapest, whose reputation as an exponent of the application of psycho-analytic methods in anthropological research has grown steadily since the War, and whose study of Australian totemism on psycho-analytic lines has recently been published in Great Britain, will visit England in the 
month of September. During his stay he will read a paper on Hungarian folklore and primitive beliefs at the Royal Anthropological Institute on a date to be announced later. Arrangements are also being made for Dr. Róheim to deliver a course of four lectures on psycho-analysis and primitive religion and magic for the Institute of Psycho-Analysis. Further particulars may be obtained from Mr. John Rickman, the hon. secretary of the Institute of Psycho-Analysis, 26 Devonshire Place, W.I, or at 42 York Terrace, N.W.r. There will be no charge for admission to Dr. Róheim's lecture at the Royal Anthropological Institute, but application for the admission of non-members should be addressed to the hon. secretary, 52 Upper Bedford Place, W.C.I, after September I.

Mr. F. Edwards, 83A High Street, Marylebone, W.I, has just issued an interesting catalogue (No. 47 I) of second-hand books, maps and charts relating to nautical subjects and the South Seas. Nearly $r_{400}$ works are listed, some of which are rare. The list can be obtained upon application.

In catalogue No. 429, Messrs. Bowes and Bowes, Cambridge, offer for sale some I Ioo second-hand volumes from the library of the late Dr. F. J. H. Jenkinson, librarian of the University of Cambridge. The books are of a miscellaneous character, but include some dealing with scientific subjects.

Messrs. W. Heffer and Sons, Ltd., Cambridge, announce for publication in the autumn " Stars and their Uses," by E. B. Leggett, a little volume in verse beginning with an introductory definition of common astronomical terms and proceeding to treat of the earth in its relation to the universe. In successive chapters it deals with the constellations, circumpolar, zodiacal, and otherwise, and concludes with remarks on the general composition of celestial bodies.

Applications are invited for the following appointments, on or before the dates mentioned: Two assistants in the department of zoology and comparative anatomy of University College, London, namely, a man, preferably with some training in physiology or chemistry, for an appointment renewable annually, and a man or a woman to take the place of an assistant absent on a year's leaveThe Secretary (August 24). An assistant lecturer in the department of pharmacy of the Technical College, Sunderland-The Chief Education Officer, I5 John Street, Sunderland (August 3I). A research chemist, a research engineer, and some junior research chemists at the Chemical Laboratory of the Department of Scientific and Industrial Research, Teddington-The Secretary, Department of Scientific and Industrial Research, I6 Old Queen Street, Westminster, S.W.I (September 4). An assistant lecturer in building construction at the Municipal College of Technology, Manchester-The Registrar (September 25). A sertior lecturer in philosophy in the University of Melbourne -The Agent-General for Victoria, Melbourne Place, Strand, W.C.2 (October I5). A temporary engineering assistant in connexion with the Air Ministry-The Secretary (S.I./437), Air Ministry, Adastral House, Kingsway, W.C.2. A junior assistant in the Agriculture Science Bureau of the International Institute of Agriculture--The General Secretary, International Institute of Agriculture, Rome.

\section{Our Astronomical Column.}

Borrelly's COMET.-A third periodic comet of the six that are due at perihelion in the present year has been found. M. Schaumasse found Borrelly's comet on August I4 at $3^{\mathrm{h}} 18 \cdot 2^{\mathrm{m}}$ univ. time in R.A. $5^{\mathrm{h}} 4^{\mathrm{m}} 24^{\mathrm{s}}$, N. Decl. $2^{\circ} 4^{\prime}$. It was of magnitude I3; the date of perihelion is about October $7 \cdot 75$. The following ephemeris (for $\mathrm{o}^{\mathrm{h}}$ ) should be near the truth:

$$
\begin{aligned}
& \begin{array}{lll}
\text { Aug. } 22 & 5^{\text {h.A. }} 26 \cdot 5^{\mathrm{m}} & \text { N. Decl. } \\
3^{\circ} 57^{\prime}
\end{array} \\
& \text {," } 30 \quad 549^{\circ} \quad 5 \quad 55 \\
& \text { Sept. } 7 \quad 6 \quad \text { 12.0 } \quad 758
\end{aligned}
$$

It is a morning object, being on the meridian about $7^{\mathrm{h}} \mathrm{I}^{\mathrm{m}}$.

Comet Hunting.-Mr. W. Reid, who has been the most successful comet hunter of recent years, contributes an interesting note on his methods to the Journal of the Astronomical Society of South Africa, vol. I, No. 5. It is particularly seasonable, since there are apparently no systematic workers in this field in the northern hemisphere, so that an amateur would have good prospects of success in it.

Mr. Reid laid down for himself the large programme of sweeping the whole southern hemisphere once a month : he found it advisable to map all the nebutæ that might be mistaken for comets. His instrument is a 6-inch Cooke photo-visual equatorial ; its definition is very fine, a point that he lays stress upon. $\mathrm{He}$ makes north and south sweeps in a fixed hour angle, the diurnal motion sufficing to give a new star field at each successive sweep. One night is devoted to the western sky, another to the eastern. There is little use in sweeping in moonlight or with bad seeing. He notes that he often sweeps for five hours or more on a good night, and yet his catches average about one per annum, so that the work requires much patience and perseverance, but he notes the sense of intense satisfaction that success brings.

Norman Lockyer Observatory, Sidmouth.The report of the Director of the Norman Lockyer Observatory, Sidmouth, for the year ended March $3 I$ last, shows that much valuable work has been accomplished during the year. Five papers on various branches of astronomy have been published, and six others are in preparation. The year was, nevertheless, a very unfavourable one with respect to weather conditions, only I33 nights having been sufficiently clear for observations to be possible ; of these, all but three were utilised. During the year the first assistant, Mr. W. B. Rimmer, left the Observatory to take up an appointment at the Canberra (Australia) Solar Physics Observatory, and from November 29 onwards the work was conducted entirely by the Director (Dr. W. J. S. Lockyer) and the chief assistant (Mr. D. L. Edwards). The principal work undertaken and completed during the year was the determination of the spectroscopic parallaxes of certain stars and the study of the spectra of some bright-hydrogen-line stars. The accounts show an excess of $73 l$. of expenditure over income, but it is hoped that, by the formation of an endowment fund, the deficiency of assured income below normal expenditure will be considerably reduced. 